Acta Crystallographica Section F

Structural Biology

and Crystallization

Communications

ISSN 1744-3091

Fabiana Lica Imai, ${ }^{a}$ Koji Nagata, ${ }^{b}$ Naoto Yonezawa, ${ }^{a}$ Jinyan $\mathrm{Yu}{ }^{\mathrm{c}}$ Eriko Ito," Saeko Kanai, ${ }^{c}$ Masaru Tanokurab $^{b}$ and Minoru Nakano ${ }^{a *}$

a Department of Chemistry, Faculty of Science, Chiba University, 1-33 Yayoi-cho, Inage-ku, Chiba 263-8522, Japan, ${ }^{\mathbf{b}}$ Graduate School of Agricultural and Life Sciences, The University of Tokyo, 1-1-1 Yayoi, Bunkyo-ku,

Tokyo 113-8657, Japan, and ${ }^{\mathrm{C}}$ Graduate School of Science and Technology, Chiba University, 1-33 Yayoi-cho, Inage-ku, Chiba 263-8522, Japan

Correspondence e-mail: mnakano@faculty.chiba-u.jp

Received 25 August 2006 Accepted 13 October 2006

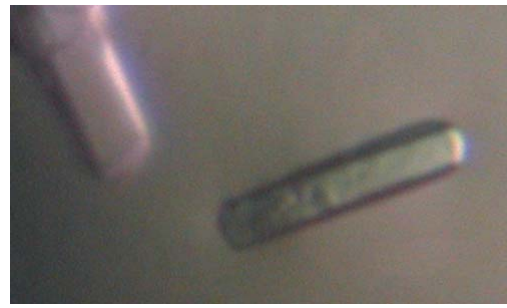

(C) 2006 International Union of Crystallography All rights reserved

\section{Crystallization and preliminary X-ray analysis of human S100A13}

S100A13 is a member of the S100 family of EF-hand-containing calcium-binding proteins and plays an important role in the secretion of fibroblast growth factor1 and interleukin $1 \alpha$, two pro-angiogenic factors released by the endoplasmic reticulum/Golgi-independent non-classical secretory pathway. Human S100A13 was heterologously expressed in Escherichia coli, purified and crystallized by the hanging-drop vapour-diffusion method using PEG 3350 as the precipitant. The crystals diffracted X-rays from a synchrotron-radiation source to $1.8 \AA$ resolution and the space group was assigned as primitive orthorhombic $P 2_{1} 2_{1} 2_{1}$.

\section{Introduction}

The S100 family of proteins are small acidic EF-hand calcium-binding proteins implicated in intracellular and extracellular regulatory activities (Donato, 1999). Within cells, most of the S100 family members exist in the form of homodimers or heterodimers. They have two different types of calcium-binding site. The N-terminal domain contains an S100-specific EF-hand-type low-affinity site, while the C-terminal domain contains a canonical EF-hand-type high-affinity site. S100A13 is a unique member of the S100 family as it is ubiquitously expressed in a broad range of tissues (Wicki et al., 1996) and does not show the conformational changes upon calcium binding that are thought to be essential for the interaction of other S100 proteins with their target proteins (Ridinger et al., 2000). S100A13 participates in the release of fibroblast growth factor-1 (FGF1) as a component of the multiprotein complex containing FGF1 and p40-synaptotagmin in response to heat shock (Carreira et al., 1998; Landriscina, Soldi et al., 2001). It is also involved in the stress-induced release of interleukin $1 \alpha$ (IL- $1 \alpha$; Mandinova et al., 2003; Prudovsky et al., 2003). FGF1 and IL-1 $\alpha$ are pro-angiogenic polypeptides which lack the classical signal peptide sequence and are secreted by the nonclassical endoplasmic reticulum/Golgi-independent pathway. The crystal structures of FGF1 and IL- $1 \alpha$ demonstrate remarkable structural similarity, despite the absence of sequence similarity (Thomas et al., 1985; Zhang et al., 1991). The interaction of S100A13 with these proteins depends on the presence of $\mathrm{Cu}^{2+}$ ions (Landriscina, Bagala et al., 2001). The $\mathrm{Cu}^{2+}$-binding sites of S100A13 are likely to be formed by $\mathrm{Ca}^{2+}$ binding (Arnesano et al., 2005), which is mediated by $\mathrm{Ca}^{2+}$ influx through $\mathrm{N}$-type $\mathrm{Ca}^{2+}$-channels (Matsunaga \& Ueda, 2006). Human S100A13 consists of 98 amino-acid residues and has a molecular weight of $11 \mathrm{kDa}$. The solution structures of the apo- and $\mathrm{Ca}^{2+}$-bound forms of human S100A13 at pH 5.6 (PDB codes 1yus and 1yuu, respectively; Arnesano et al., 2005) have previously been reported. Here, we report the crystallization of $\mathrm{Ca}^{2+}$-bound human S100A13 at physiological pH ( $\mathrm{pH} 7.5)$.

\section{Materials and results}

\subsection{Cloning of human S100A13}

Human S100A13 cDNA (GenBank accession No. AK097132) cloned from a first-strand cDNA library from human spleen (Origene Technologies) was amplified by polymerase chain reaction (PCR) and subcloned into the $N d e \mathrm{I} /$ Bam HI site of the pET-16b vector (Novagen). 
Table 1

Crystal parameters of S100A13.

Values in parentheses are for the highest resolution shell.

\begin{tabular}{ll}
\hline Wavelength $(\AA)$ & 1.000 \\
Space group & $P 2_{1} 2_{1} 2_{1}$ \\
Unit-cell parameters $(\AA)$ & $a=39.7, b=59.2, c=77.6$ \\
Resolution range $(\AA)$ & $50.0-1.80(1.86-1.80)$ \\
Observed reflections & 122381 \\
Unique reflections & 17786 \\
Data completeness (\%) & $99.1(93.0)$ \\
Redundancy & $6.9(6.3)$ \\
$R_{\text {sym }} \dagger$ & $0.066(0.335)$ \\
$\langle I / \sigma(I)\rangle$ & $30.7(3.4)$ \\
\hline
\end{tabular}

$\dagger R_{\text {sym }}=\sum_{h k l} \sum_{i}\left|I_{h k l, i}-\left\langle I_{h k l}\right\rangle\right| / \sum_{h k l} \sum_{i}\left\langle I_{h k l}\right\rangle$, where $I_{i}$ is the $i$ th observation of reflection $h k l$ and $\left\langle I_{h k l}\right\rangle$ is the weighted average intensity for all observations $i$ of reflection $h k l$.

\subsection{Purification of recombinant human S100A13}

Escherichia coli BL21(DE3) cells harbouring the expression vector pET-16b-human S100A13 were grown at $310 \mathrm{~K}$. The expression of S100A13 with an N-terminal $10 \times$ His tag and a Factor Xa proteasecleavage site (MGHHHHHHHHHHSSGHIEGR $\downarrow$ HM..., where the arrow to the C-terminal side of the italicized IEGR sequence indicates the Factor Xa cleavage site and the $\mathrm{M}$ in bold is the $\mathrm{N}$-terminal methionine residue of S100A13) was induced at an $\mathrm{OD}_{600}$ of 0.6 with $1 \mathrm{~m} M$ isopropyl 1-thio- $\beta$-galactopyranoside (IPTG) and the culture continued at $310 \mathrm{~K}$ for $4 \mathrm{~h}$. The cells were harvested by centrifugation at $3000 \mathrm{~g}$ for $10 \mathrm{~min}$ at $277 \mathrm{~K}$. The cells were resuspended in $50 \mathrm{mM}$ Tris- $\mathrm{HCl} \mathrm{pH} 8.0$, disrupted by sonication and centrifuged at $26000 \mathrm{~g}$ for $20 \mathrm{~min}$ at $277 \mathrm{~K}$. The supernatant was

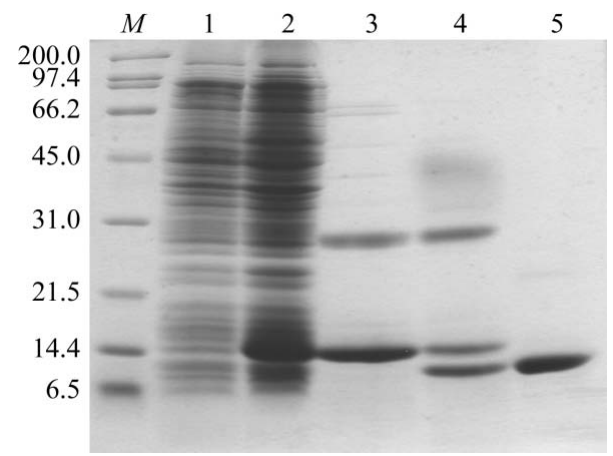

Figure 1

SDS-PAGE (15\%) analysis of recombinant human S100A13 protein. Lanes 1 and 2, E. coli cell lysate before and after induction with IPTG, respectively. Lane 3, $10 \times$ His-tagged S100A13 eluted from His-Bind Resin. Lane 4, after cleavage of the $10 \times$ His tag from S100A13 with Factor Xa protease. Lane 5, S100A13 purified by anion-exchange chromatography. Lane $M$, protein markers (kDa).

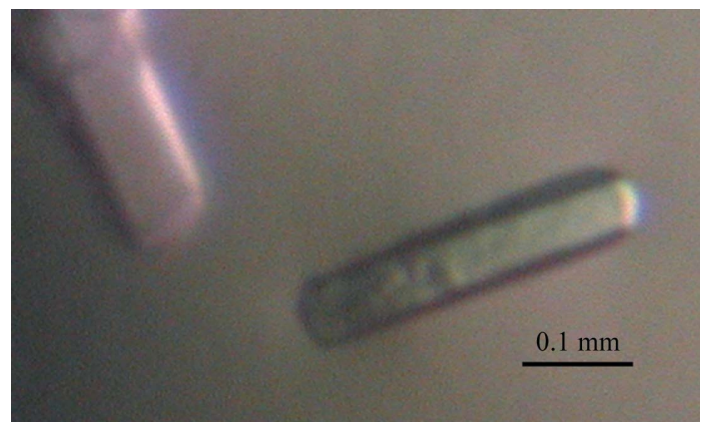

Figure 2

Crystals of human S100A13 with approximate dimensions of $0.25 \times 0.05 \times 0.05 \mathrm{~mm}$ grown at $293 \mathrm{~K}$ using PEG 3350 as the precipitant. subjected to His-Bind affinity chromatography precharged with $\mathrm{Ni}^{2+}$ (Novagen). $10 \times$ His-tagged human S100A13 was eluted with $1.0 \mathrm{M}$ imidazole, $500 \mathrm{~m} M \mathrm{NaCl}$ and $20 \mathrm{~m} M$ Tris- $\mathrm{HCl} \mathrm{pH}$ 7.9. The eluted protein was dialyzed against $100 \mathrm{~m} M \mathrm{NaCl}, 5 \mathrm{~m} M \mathrm{CaCl}_{2}$ and $50 \mathrm{~m} M$ Tris $-\mathrm{HCl} \mathrm{pH} 8.0$ at $277 \mathrm{~K}$ overnight. The $10 \times$ His tag was cleaved off by incubating the His-tagged protein with Factor Xa protease (Novagen, $10 \mathrm{U}$ of enzyme per milligram of protein substrate) at room temperature for $4 \mathrm{~h}$, which resulted in human S100A13 with an additional histidine residue at the $\mathrm{N}$-terminus. The cleavage reaction was stopped by the addition of $1 \mathrm{~m} M$ AEBSF (Roche). The cleaved protein was then dialyzed against $25 \mathrm{mM}$ Tris- $\mathrm{HCl} \mathrm{pH} 8.1$ and applied onto an Econo-Pac High Q (Bio-Rad) anion-exchange column equilibrated with the same buffer and eluted with a linear gradient of $0-0.1 \mathrm{M} \mathrm{NaCl}$. Fractions containing the purified S100A13 were concentrated to $7.4 \mathrm{mg} \mathrm{ml}^{-1}$ using Vivaspin 20 concentrators (Vivascience). The purity was ascertained by SDS-PAGE and the concentration was determined from the absorbance at $280 \mathrm{~nm}$. The purity of the sample was assessed by SDS-PAGE as shown in Fig. 1.

\subsection{Crystallization}

Crystallization experiments were performed at $293 \mathrm{~K}$ by the hanging-drop vapour-diffusion method using VDX 24-well crystallization plates (Hampton Research) and the crystallization screening kits Crystal Screens 1 and 2 (Hampton Research) and Wizards I and II (Emerald Biostructures). Calcium chloride was added to the protein solution to a final concentration of $2 \mathrm{mM}$ prior to crystallization in order to obtain a calcium-bound form of S100A13. Crystals appeared in the presence of polyethylene glycol (PEG) 3350 (Hampton Research) as the precipitant. After refinement of the crystallization conditions, crystals suitable for X-ray analysis were obtained in two weeks by mixing $0.5 \mu \mathrm{l}$ protein solution $\left(7.4 \mathrm{mg} \mathrm{ml}^{-1}\right.$ in $25 \mathrm{~m} M$ Tris- $\mathrm{HCl} \mathrm{pH} 8.1,0.1 \mathrm{M} \mathrm{NaCl}$ and $2 \mathrm{~m} M \mathrm{CaCl}_{2}$ ) and $0.5 \mu \mathrm{l}$ reservoir solution consisting of $22 \%(w / v)$ PEG 3350, $0.1 M$ HEPES-

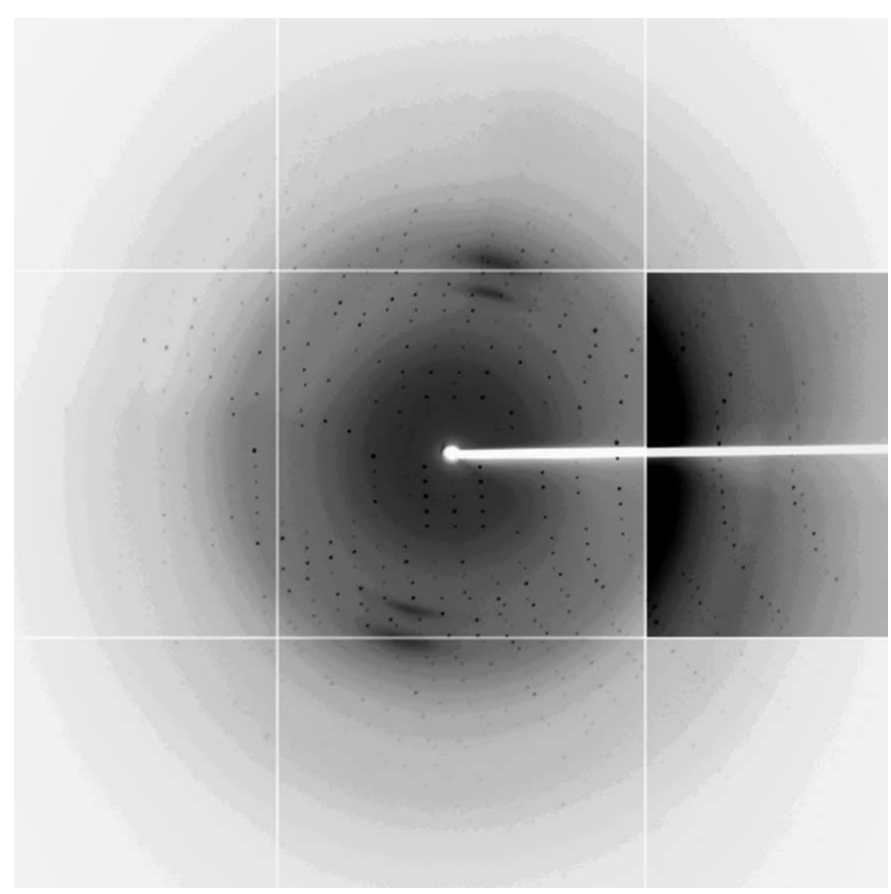

Figure 3

An X-ray diffraction image ( $1^{\circ}$ oscillation) of a human S100A13 crystal. The edge of the diffraction image corresponds to a resolution of $1.80 \AA$. The contrast is enhanced in the right middle panel so that weak diffraction spots can be seen. 
$\mathrm{NaOH} \mathrm{pH}$ 7.5, $0.2 \mathrm{M} \mathrm{NaCl}$ and $1.5 \%(w / v)$ 1,2,3-heptanetriol. A drop was equilibrated against $500 \mu \mathrm{l}$ reservoir solution at $293 \mathrm{~K}$. Fig. 2 shows typical crystals (approximate dimensions $0.25 \times 0.05 \times$ $0.05 \mathrm{~mm})$.

\subsection{X-ray data collection and processing}

A crystal of S100A13 was picked up in a nylon loop (Hampton Research), transferred to a cryoprotectant solution containing $20 \%(v / v)$ glycerol, 17.6\%( $w / v)$ PEG 3350, $0.08 M$ HEPES-NaOH pH 7.5, $0.16 \mathrm{M} \mathrm{NaCl}$ and $1.2 \%(w / v)$ 1,2,3-heptanetriol and then flashcooled at $100 \mathrm{~K}$ in a nitrogen stream. X-ray diffraction data were collected at beamline BL41XU equipped with an ADSC Quantum 315 detector at SPring-8 (Harima, Japan). An X-ray diffraction data set consisting of 180 images was collected with a wavelength of $1.000 \AA$, a crystal-to-detector distance of $200 \mathrm{~mm}$, an oscillation angle of $1^{\circ}$ and an exposure time of $4.0 \mathrm{~s}$. The crystals diffracted beyond $1.8 \AA$ resolution (Fig. 3). The diffraction data were indexed, integrated and scaled using $H K L-2000$ (Otwinowski \& Minor, 1997). The space group of the crystals was determined as $P 2_{1} 2_{1} 2_{1}$ (the data statistics are shown in Table 1). The crystal contained two S100A13 molecules per asymmetric unit according to the Matthews coefficient $\left(V_{\mathrm{M}}=2.0 \AA^{3} \mathrm{Da}^{-1}\right)$ and a solvent content of $38 \%$. Structure solution and refinement is in progress.

Synchrotron-radiation experiments were performed at SPring-8 (Harima, Japan) with the approval of Japan Synchrotron Radiation Research Institute (Proposal Nos. 2006A2721 and 2006A2728). This work was supported in part by the National Project on Protein Structural and Functional Analyses of Ministry of Education, Culture, Sports, Science and Technology of Japan and by Grants-inAid from The Japan Society for the Promotion of Science (JSPS).

\section{References}

Arnesano, F., Banci, L., Bertini, I., Fantoni, A., Tenori, L. \& Viezzoli, M. S. (2005). Angew. Chem. Int. Ed. 44, 2-5.

Carreira, C. M., La Vallee, T. M., Tarantini, F., Jackson, A., Lathrop, J. T., Hampton, B., Burgess, W. H. \& Maciag, T. (1998). J. Biol. Chem. 273, 22224 22231.

Donato, R. (1999). Biochim. Biophys. Acta, 1450, 191-231.

Landriscina, M., Bagala, C., Mandinova, A., Soldi, R., Micucci, I., Bellum, S., Prudovsky, I. \& Maciag, T. (2001). J. Biol. Chem. 276, 25549-25557.

Landriscina, M., Soldi, R., Bagala, C., Micucci, I., Bellum, S., Tarantini, F., Prudovsky, I. \& Maciag, T. (2001). J. Biol. Chem. 276, 22544-22552.

Mandinova, A., Soldi, R., Graziani, I., Bagala, C., Bellum, S., Landriscina, M., Tarantini, F., Prudovsky, I. \& Maciag, T. (2003). J. Cell Sci. 116, 2687-2696.

Matsunaga, H. \& Ueda, H. (2006). Cell. Mol. Neurobiol. 26, 237-246.

Otwinowski, Z. \& Minor, W. (1997). Methods Enzymol. 276, 307-326.

Prudovsky, I., Mandinova, A., Soldi, R., Bagala, C., Graziani, I., Landriscina, M., Tarantini, F., Duarte, M., Bellum, S., Doherty, H. \& Maciag, T. (2003). J. Cell Sci. 116, 4871-4881.

Ridinger, K., Schafer, B. W., Durussel, I., Cox, J. A. \& Heizmann, C. W. (2000). J. Biol. Chem. 275, 8686-8694.

Thomas, K. A., Rios-Candelore, M., Gimenez-Gallego, G., DiSalvo, J., Bennett, C., Rodkey, J. \& Fitzpatrick, S. (1985). Proc. Natl Acad. Sci. USA, 82, 6409-6413.

Wicki, R., Schafer, B. W., Erne, P. \& Heizmann, C. W. (1996). Biochem. Biophys. Res. Commun. 227, 594-599.

Zhang, J. D., Cousens, L. S., Barr, P. J. \& Sprang, S. R. (1991). Proc. Natl Acad. Sci. USA, 88, 3446-3450. 